\title{
IMPACT OF IRON DEFICIENCY ON DIAGNOSIS OF BETA THALASSEMIA TRAIT.
}

1. M.Phil, Ph. D

Associate Professor \& HOD Pathology

The Children's Hospital \& the Institute of Child Health Multan.

2. M.Phil

Assistant Professor Pathology

University Medical \& Dental College, The University of Faisalabad, Faisalabad.

3. FCPS (Histopathology) Assistant Professor Histopathology Independent Medical University Faisalabad.

Correspondence Address: Asma Naseer Cheema

Associate Professor \& HOD Pathology The Children's Hospital \& the Institute of Child Health Multan

asma.cheema4@gmail.com

Article received on:

28/10/2019

Accepted for publication:

29/12/2019

\begin{abstract}
Asma Naseer Cheema1, Rubya Khanum², Shireen Hamid ${ }^{3}$
\end{abstract}
ABSTRACT... Objectives: We aimed to evaluate the effect of low serum ferritin levels on $\mathrm{HbA} 2$ values in Beta thalassemia trait (BTT) patients. Study Design: Cross-sectional study. Setting: Pathology department of University Medical \& Dental College Faisalabad. Period: August, 2018 to July, 2019. Materials \& Methods: One hundred and thirty seven subjects were included in the study after written informed consent. Those with serum ferritin $<10 \mu \mathrm{g} / \mathrm{L}$ were taken as iron deficient. Based on serum ferritin levels, we divided our study participants into two groups (Group A Vs Group B). As ferritin is considered an acute-phase protein, 25/137 participants with leukocytosis were excluded from statistical analysis. We measured serum Ferritin on Cobas $6000 \mathrm{e} 611$ and we assessed the red cell parameters on Sysmex (seven part differential XN 1000). $\mathrm{Hb}$ variants were analysed through High performance liquid chromatography (HPLC) based technique of BioRad D10. Results: After excluding 25 subjects with high Total leukocyte count (TLC), we were left with 112 subjects. We observed 26 participants in group A with Iron deficiency and 38 in group $B$ with no Iron deficiency. Mean \pm SD serum ferritin in iron deficient group was $7.25 \pm 1.95$ as compared to non-iron deficient group $(87.63 \pm 7.35)$. Mean $\mathrm{HbA} 2$ value in group $A$ was $4.56 \pm 0.04$ and in group $B$ it was $5.80 \pm 1.06$ with significant statistical difference of $\mathrm{P}=0.0188$. We also observed significant difference in the mean values of other Red cell indices (MCV, HCT MCHC, MCH) except for RBC count and RDW. Conclusion: This study shows that ID may reduce $\mathrm{HbA} 2$ levels. Overall, it does not essentially preclude the identification of $\mathrm{BTT}$. It is recommended that Iron deficiency should be considered before measuring HbA2 levels in BTT.

Key Words: Beta Thalassemia Trait, HbA2, Iron Deficiency.

Article Citation: Cheema AN, Khanum R, Hamid S. Impact of Iron deficiency on diagnosis of Beta Thalassemia Trait. Professional Med J 2020; 27(4):849-852.

DOI: 10.29309/TPMJ/2020.27.04.4297

\section{INTRODUCTION}

Laboratory diagnosis of BTT can be made by estimating the concentration of $\mathrm{HbA} 2$ protein. Among genetic disorders, hemoglobinopathy is the only disorder that can be determined through its phenotype on $\mathrm{Hb}$ electrophoresis. ${ }^{1}$ Haemoglobin $A_{2}\left(\mathrm{HbA}_{2}\right.$ : a2d2) estimation is the main parameter which is measured worldwide for identification of BTT. Comparable quantification of $\mathrm{HbA} 2$ has been achieved by High performance liquid chromatography (HPLC), ${ }^{2}$ Capillary zone electrophoresis, Cellulose Acetate electrophoresis-elution spectrophotometry or Microcolumn chromatography (MCC). So, any effect of assay interference is excluded. ${ }^{3}$

Iron homeostasis has complex interplay with BTT. Researchers have observed that iron balance goes in favour of BTT patients as compared to controls. ${ }^{4}$ This is due to increased iron absorption in the background of small sized RBCs with less oxygen carrying capacity. However some of the studies observed the presence of Iron deficiency (ID) in about $30 \%$ cases. ${ }^{5}$ Iron is bound to heme portion of hemoglobin. Less iron availability definitely reduces the overall $\mathrm{Hb}$ concentration and might affect the $\mathrm{HbA}_{2}$ value either. ${ }^{6}$ This may mask the presence of BT trait and pose a major challenge for the screening laboratories in the diagnosis of BT trait. ${ }^{7}$ Situation is even gruesome in under-privileged settings like Pakistan where iron deficiency is highly prevalent. Since Concomitant iron deficiency has a potential impact on $\mathrm{HbA}_{2}$ therefore, the objective of this study was to evaluate the effect of low serum ferritin levels on $\mathrm{HbA} 2$ values in BTT patients. 


\section{MATERIALS \& METHODS}

This was a cross-sectional study and performed in Pathology department of University Medical \& Dental College Faisalabad between August, 2018 to July, 2019.

One hundred and thirty seven subjects were included in the study after written informed consent. Based on serum ferritin levels we divided our study participants into two groups (Group A: Iron deficient with serum ferritin $<10 \mu \mathrm{g} / \mathrm{L} \mathrm{Vs}$ Group B: Non iron deficient with serum ferritin $\geq 10$ $\mu \mathrm{g} / \mathrm{L})$. As ferritin is considered an acute-phase protein, 25/137 participants with leukocytosis were excluded from statistical analysis. We measured serum ferritin on Cobas 6000 e611 and we assessed the red cell parameters on Sysmex (seven part differential $\mathrm{XN}$ 1000). Hb variants were analysed through High performance liquid chromatography (HPLC) based technique of BioRad D10. Statistal package of Social Sciences (SPPS) version 23.00 was used for statistical analysis. Red cell indices, serum ferritin and $\mathrm{HbA} 2$ were compared between two groups using independent sample t-test. The result were considered significant when P-value was $<0.05$.

\section{RESULTS}

After excluding 25 subjects with high total leukocyte count (TLC) count, we are left with 112 subjects for thalassemia screening. The subjects with high clinical suspicion of BTT were separated to assess for hemoglobinopathy. 64/112 subjects were observed with high $\mathrm{HbA} 2$ values (>3.5\%). Majority of the participants (40/64) were female. Mean $\mathrm{Hb}$ levels of female were $9.0 \pm 0.5 \mathrm{~g} / \mathrm{dL}$ Vs male 10.5 $\pm 0.10 \mathrm{~g} / \mathrm{dL}(P=0.231)$.

Twenty six subjects were found in group A with Iron deficiency and thirty six in group B without Iron deficiency. Mean serum ferritin in group A was_7.25 \pm 1.95 as compared to group B 87.63 \pm 7.35. Mean $\mathrm{HbA2}$ value in group $\mathrm{A}$ Vs group B was: $4.56 \pm 0.04(\%)$ Vs $5.80 \pm 1.06$ (\%) with significant statistical difference of $\mathrm{P}=0.0188$ (Figure 1). There was also significant difference in the mean values of other Red cell indices (MCV, $\mathrm{HCT} \mathrm{MCHC}, \mathrm{MCH}$ ) except for RBC count and RDW. (Table-I).

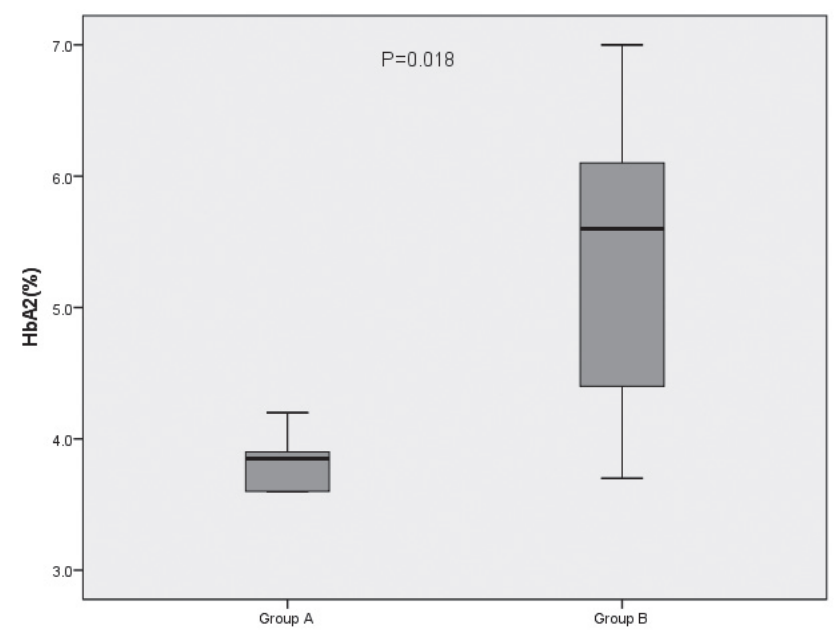

Figure-1: HbA2 levels in Iron deficient (A) Vs. Non iron deficient (B).

\begin{tabular}{|l|c|c|c|}
\hline \multicolumn{1}{|c|}{ Red Cell indices } & Group A (Mean \pm SD) & Group B(Mean \pm SD) & P-value \\
\hline $\mathrm{Hb}(\mathrm{g} / \mathrm{dL})$ & $9.72 \pm 2.18$ & $11.81 \pm 1.34$ & 0.007 \\
\hline $\mathrm{RBC}$ count $\left(10^{12} / \mathrm{L}\right)$ & $5.93 \pm 0.57$ & $6.50 \pm 0.38$ & 0.497 \\
\hline $\mathrm{HCT}(\%)$ & $32.32 \pm 5.36$ & $37.95 \pm 4.82$ & 0.010 \\
\hline $\mathrm{MCH}(\mathrm{pg})$ & $14.90 \pm 2.93$ & $19.02 \pm 1.69$ & $<0.001$ \\
\hline $\mathrm{MCV}(\mathrm{fL})$ & $50.43 \pm 6.08$ & $58.36 \pm 2.71$ & 0.010 \\
\hline $\mathrm{MCHC}(\mathrm{g} / \mathrm{dL})$ & $29.46 \pm 2.10$ & $31.70 \pm 0.38$ & 0.004 \\
\hline $\mathrm{RDW}-\mathrm{CV}(\%)$ & $21.18 \pm 4.13$ & $18.62 \pm 2.39$ & 0.09 \\
\hline & Table-l. Red cell indices in Iron deficient Vs non-Iron deficient subjects with BTT. \\
\hline
\end{tabular}




\section{DISCUSSION}

Beta Thalassemia Major (BTM) is an inherited hematological disorder with a global incidence of one in $100,000 .^{8-9}$ Genetic derangement causes diminished synthesis of beta globin chain that leads to ineffective erythropoises requiring lifelong blood transfusion. ${ }^{10}$ However, BTT with single allele mutation usually remains asymptomatic. A probable diagnosis can be made on the basis of red cell indices but it needs to be confirmed on $\mathrm{Hb}$ electrophoresis. ${ }^{11-12}$ Detection of BT trait among the masses is critical to reduce the prevalence of BTM in the society by pre marriage counselling.

IDA and thalassemia are the main causes of Microcytic hypochromic blood picture in children and adults. ${ }^{13}$ Previously it was thought that ID is not present in thalassemic subjects including both thalassemia major and trait. ${ }^{14}$ But later studies showed concomitant existence of both iron deficiency and BTT. We found that $26(23 \%)$ BTT subjects were iron deficient in our study cohort which is relatively high percentage in any population. The high incidence of ID is substantiated by other studies. Sharma et al., and Dolai et al reported the frequencies of $20.7 \%$ and $19.3 \%$ respectively. ${ }^{5,15}$

It has been observed that $\mathrm{HbA} 2$ levels fall in those BTT subjects who also have coexisting iron deficiency. However some of the studies did not show any significant effect of ID on $\mathrm{HbA} 2$ levels. ${ }^{16-17}$ Our study also showed relatively low concentration of $\mathrm{HbA} 2$ value in $\mathrm{BTT}$ subjects with coexisting ID but $\mathrm{HbA} 2$ value was still above its cutoff $(>3.5 \%)$. It has been concluded by one of the studies that $\mathrm{Hb}$ levels in BTT cannot indicate the presence of co-existing ID. The process of erythropoises becomes relatively active in BTT subjects with high RBC count. ${ }^{18}$ In contrast to this ID leads to low RBC count and slow rate of erythropoises due to lack of Iron nutrient. ${ }^{19}$ Combined existence of these two conditions may lead to near normal RBC count. We observed this phenomenon very clearly in our study population where RBC count was relatively low in BTT subjects with ID. The low serum ferritin levels were observed in female subjects as compared to male. The iron supplementation is more critical for females than males.

We also observed two cases who had strong suspicion of BTT based on their red cell indices (RBC count, $\mathrm{MCH}, \mathrm{MCHC}, \mathrm{RDW}, \mathrm{RDW}-\mathrm{I}$ ) and had low ferritin. Their $\mathrm{HbA} 2$ value was between 3.0-3.5. These borderline cases need to be reevaluated after correcting IDA.

These borderline cases with coexisting ID should have been excluded from diagnosis of BTT based on genetic testing. Due to lack of genetic testing in our lab, we just excluded their diagnosis of BTT on the basis of HbA2 value. It is suggested that such cases should be tested again after correcting ID anemia through $\mathrm{Hb}$ electrophoresis where genetic testing is not available.

\section{CONCLUSION}

In summary, we conclude that that ID may decrease HbA2 levels. Generally, it does not preclude the diagnosis of BTT. This study also indicates the high incidence of coexisting ID and BTT. The diagnosis of BTT may be affected in these subjects. Therefore, it is very important to first correct the ID in the subjects with high suspicion of BTT before measuring $\mathrm{HbA} 2$.

\section{Copyright 29 Dec, 2019.}

\section{REFERENCES}

1. Sachdev R, Dam AR, Tyagi G. Detection of Hb variants and hemoglobin opathies in Indian population using HPLC: report of 2600 cases. Indian journal of pathology and microbiology. 2010 Jan 1; 53(1):57.

2. Van Kirk R, Sandhaus LM, Hoyer JD. The detection and diagnosis of hemoglobin A2'by high-performance liquid chromatography. American journal of clinical pathology. 2005 May 1; 123(5):657-61.

3. Brants A. Detection of hemoglobin opathies and thalassemia's using automated separation systems. Medical Laboratory Observer. 2014 Jan.

4. Riva A, Mariani R, Bovo G, Pelucchi S, Arosio C, Salvioni A, Vergani A, Piperno A. Type 3 hemochromatosis and $\boldsymbol{\beta} \square$ thalassemia trait. European journal of haematology. 2004 May; 72(5):370-4. 
5. Verma S, Gupta R, Kudesia M, Mathur A, Krishan G, Singh S. Coexisting iron deficiency anemia and Beta thalassemia trait: effect of iron therapy on red cell parameters and hemoglobin subtypes. ISRN hematology. 2014 Mar 12; 2014.

6. Mehta BC, Pandya BG. Iron status of beta thalassemia carriers. American journal of hematology. 1987 Feb; 24(2):137-41.

7. Lin CK, Chen LP, Chang HL, Sung YC. Underestimation of the coexistence of iron deficiencies and thalassemia minors: a single institution experience in Taiwan. The Kaohsiung journal of medical sciences. 2014 Aug 1; 30(8):409-14.

8. Origa R. $\boldsymbol{\beta}$-Thalassemia. Genetics in Medicine. 2017 Jun; 19(6):609.

9. Mondal SK, Mandal S. Prevalence of thalassemia and hemoglobinopathy in eastern India: a 10-year high-performance liquid chromatography study of 119,336 cases. Asian journal of transfusion science. 2016 Jan; 10(1):105.

10. Hershko C. Pathogenesis and management of iron toxicity in thalassemia. Annals of the New York Academy of Sciences. 2010 Aug; 1202(1):1-9.

11. Vehapoglu A, Ozgurhan G, Demir AD, Uzuner S, Nursoy MA, Turkmen S, Kacan A. Hematological indices for differential diagnosis of Beta thalassemia trait and iron deficiency anemia. Anemia. 2014; 2014.

12. Madan N, Sikka M, Sharma S, Rusia U. Phenotypic expression of hemoglobin A 2 in beta-thalassemia trait with iron deficiency. Annals of hematology. 1998 Sep 1; 77(3):93-6.
13. Beyan C, Kaptan K, Ifran A. Predictive value of discrimination indices in differential diagnosis of iron deficiency anemia and beta $\square$ thalassemia trait. European journal of haematology. 2007 Jun; 78(6):5246.

14. Kattamis $\mathrm{CH}$, Lagos $\mathrm{PA}$, Metaxotou-Mavromati $\mathrm{AN}$, Matsaniotis NI. Serum iron and unsaturated ironbinding capacity in the-thalassaemia trait: their relation to the levels of haemoglobins A, A 2, and F. Journal of medical genetics. 1972 Jun; 9(2):154.

15. Dolai TK, Nataraj KS, Sinha N, Mishra S, Bhattacharya $M$, Ghosh MK. Prevalance of iron deficiency in thalassemia minor: a study from tertiary hospital. Indian Journal of Hematology and Blood Transfusion. 2012 Mar 1; 28(1):7-9.

16. Passarello C, Giambona A, Cannata M, Vinciguerra $M$, Renda D, Maggio A. Iron deficiency does not compromise the diagnosis of high $\mathrm{HbA2}$ $\boldsymbol{\beta}$ thalassemia trait. Haematologica. 2012 Mar1; $97(3): 472-3$.

17. El-Agouza I, Abu Shahla A, Sirdah M. The effect of iron deficiency anaemia on the levels of haemoglobin subtypes: possible consequences for clinical diagnosis. Clinical \& laboratory haematology. 2002 Oct; 24(5):285-9.

18. Jones E, Pasricha SR, Allen A, Evans P, Fisher CA, Wray K, Premawardhena A, Bandara D, Perera A, Webster C, Sturges $P$. Hepcidin is suppressed by erythropoiesis in hemoglobin $E$-thalassemia and $\boldsymbol{\beta}$-thalassemia trait. Blood. 2015 Jan 29; 125(5):873-80.

19. Goodnough LT. Iron deficiency syndromes and ironrestricted erythropoiesis (CME). Transfusion. 2012 Jul; 52(7):1584-92.

\begin{tabular}{|c|l|l|l|}
\hline \multicolumn{3}{|c}{ AUTHORSHIP AND CONTRIBUTION DECLARATION } \\
\hline Sr. \# & \multicolumn{1}{|c|}{ Author(s) Full Name } & \multicolumn{1}{|c|}{ Contribution to the paper } & Author(s) Signature \\
\hline 1 & Asma Naseer Cheema & $\begin{array}{l}\text { Conception of idea, Data collection, } \\
\text { analysis, writing in manuscript. } \\
\text { Writing of review. }\end{array}$ \\
\hline 2 & Rubya Khanum & Writing of review. & \\
\hline 3 & Shireen Hamid & W
\end{tabular}

